\title{
Water Loss from the Skin of Term and Preterm Infants Nursed under a Radiant Heater
}

\author{
SVEINN KJARTANSSON, SAADET ARSAN, KAREN HAMMARLUND,${ }^{1}$ GUNNAR SJÖRS, AND \\ GUNNAR SEDIN
}

Department of Pediatrics, University Hospital, Uppsala, Sweden

\begin{tabular}{|c|c|}
\hline ABST & RACT \\
\hline $\begin{array}{l}\text { The rate of evaporation from the skin }\left(\mathrm{g} / \mathrm{m}^{2} / \mathrm{h}\right) \text { was measured } \\
\text { in } 12 \text { full-term and } 16 \text { preterm infants (gestational age } 25-34 \mathrm{wk} \text { ) } \\
\text { both during incubator care and when nursed under a radiant } \\
\text { heater. The method for evaporation rate measurement is nonin- } \\
\text { vasive and based on determination of the water vapor pressure } \\
\text { gradient close to the skin surface. Measurements were first made } \\
\text { with the infant nursed in an incubator with a controlled environ- } \\
\text { ment with respect to humidity, temperature, and air velocity. The } \\
\text { measurements in the term infants were performed at an ambient } \\
\text { relative humidity (RH) of } 50 \% \text {, and in the preterm infants first at } \\
50 \% \text { and subsequently at } 30-40 \% \text {. Evaporation rate was then } \\
\text { measured with the infant nursed under a radiant heater. In term } \\
\text { infants, mean evaporation rate was } 3.3 \mathrm{~g} / \mathrm{m}^{2} / \mathrm{h} \text { during incubator } \\
\text { care (RH } 50 \% \text { ) and } 4.4 \mathrm{~g} / \mathrm{m}^{2} / \mathrm{h} \text { during care under the radiant } \\
\text { heater. In preterm infants, the corresponding values were } 15.5 \\
\mathrm{~g} / \mathrm{m}^{2} / \mathrm{h} \text { in the incubator at RH } 50 \%, 16.7 \mathrm{~g} / \mathrm{m}^{2} / \mathrm{h} \text { at RH } 30-40 \% \text {, } \\
\text { and } 17.9 \mathrm{~g} / \mathrm{m}^{2} / \mathrm{h} \text { under the radiant heater. It is concluded that the } \\
\text { evaporative water loss from the skin depends on the ambient } \\
\text { water vapor pressure, irrespective of whether the infant is nursed }\end{array}$ & $\begin{array}{l}\quad \text { Abbreviations } \\
\mathbf{E R} \text {, evaporation rate } \\
\mathbf{P H}_{\mathbf{2}} \mathbf{O} \text {, water vapor pressure } \\
\mathbf{R H} \text {, relative humidity } \\
\mathbf{H R} \text {, heart rate } \\
\mathbf{R R} \text {, respiratory rate } \\
\mathbf{R} \mathbf{H}_{\text {amb }} \text {, ambient relative humidity } \\
\mathbf{P H}_{\mathbf{2}} \mathbf{O}_{\text {amb }} \text {, ambient water vapor pressure } \\
\mathbf{T}_{\text {body }} \text {, rectal temperature } \\
\mathbf{T}_{\text {isc }} \text {, interscapular skin temperature } \\
\mathbf{T}_{\text {leg }} \text {, leg skin temperature } \\
\mathbf{T}_{\text {amb }} \text {, ambient temperature }\end{array}$ \\
\hline
\end{tabular}

Radiant heaters are frequently used in the care of newborn infants and are considered to be effective in rewarming infants exposed to cold stress after birth (1). One possible disadvantage of radiant heaters is that they may cause dehydration in the newborn by increasing insensible water loss (2-8). The mechanism of such an increase is not understood and appropriate methods for measuring the effect of nonionizing radiation have been difficult to find.

In previous studies (2-8) concerning the effect of nonionizing radiant energy, produced either by radiant heaters or by phototherapy, insensible water loss was determined by indirect methods (gravimetric methods, usually using the Potter scale), making it difficult to ascertain whether the observed increase derived from an increase in transepidermal or respiratory water

Received February 24, 1994; accepted September 1, 1994.

Correspondence: Professor Gunnar Sedin, Department of Pediatrics, University Children's Hospital, S-751 85 Uppsala, Sweden.

Supported by grants from the Swedish Medical Research Council (Project 19X-04998), the newspaper Expressen's Prenatal Research Foundation, Stockholm, Sweden, and the Swedish Institute (fellowship for S.A.).

${ }^{1}$ This was one of Karen Hammarlund's last scientific contributions; she died before publication of the study. loss. Various explanations for the higher insensible water loss observed have been proposed. Williams and Oh (2) and Bell and $\mathrm{Oh}$ (9) suggested that the vapor pressure of the ambient air may be lower under the radiant heater than in an incubator and could result in a higher vapor pressure gradient and a higher loss of water from the skin and respiratory tract. Baumgart et al. (7) found that in critically ill preterm infants nursed under a radiant heater there was a significant increase in insensible water loss as radiant power density increased and suggested that small infants require more radiant power density to maintain body temperature and that they incur much greater insensible water loss when compared with larger, more mature infants. Baumgart et al. $(8,10)$ also proposed that convective air currents under a radiant heater could be the cause of an increase in evaporation.

We have previously used the gradient method to study the ER from the skin of term and preterm newborn infants under different environmental conditions (11-15). Recently we have shown that the measurement technique used in our study is not significantly influenced by the radiation from the radiant heater at the energy output levels used in this study (16). Wheldon 
and Rutter (17) applied the same technique to study the effect of radiant heat and claimed that radiant heat altered the resistance of the skin to water vapor diffusion, resulting in an increase in evaporative water loss.

In another study, the effect of phototherapy on the water loss from the skin was investigated by measuring the ER directly from a skin area exposed to phototherapy. We found no change in the ER during phototherapy in thermally stable term or preterm infants (18).

Our aim was to determine the effect of radiant energy from an overhead radiant heater on the ER from the skin in newborn infants. Measurements of this rate were made directly from the skin area exposed to radiant heat.

\section{METHODS}

\section{Subjects}

The ER $\left(\mathrm{g} / \mathrm{m}^{2} / \mathrm{h}\right)$ was measured from the skin of 12 term and 16 preterm infants, all of whom had an appropriate birth weight for gestational age.

The term infants (group I; $n=12$ ) were born after a mean gestation of $39 \mathrm{wk}$ (range 37-41 wk), had a mean birth weight of $3.676 \mathrm{~kg}$ (range $3.200-4.040 \mathrm{~kg}$ ), and were all apparently healthy. Their mean postnatal age at the start of the measurements was $7 \mathrm{~h}$ (range 4-11 h).

The preterm infants were divided into two groups (groups II and III). Group II $(n=8)$ comprised moderately preterm infants with a mean gestational age of $31.8 \mathrm{wk}$ (range 30-34 wk) and a mean birth weight of $1.795 \mathrm{~kg}$ (range 1.233-2.550 $\mathrm{kg}$ ). Their mean postnatal age at the start of the measurements was $6 \mathrm{~d}$ (range 1-9 d, median $5 \mathrm{~d}$ ).

Group III $(n=8)$ comprised very preterm infants with a mean gestational age of $27.1 \mathrm{wk}$ (range $25-29 \mathrm{wk}$ ) and a mean birth weight of $1.126 \mathrm{~kg}$ (range $0.695-1.736 \mathrm{~kg}$ ). Their mean postnatal age at the start of the measurements was $6 \mathrm{~d}$ (range 1-19 d, median $3 \mathrm{~d}$ ). Four of the infants needed ventilatory support with nasal continuous positive airway pressure during the measurements. All infants were in a stable condition at the time of the measurements. All the preterm infants were fed breast milk through an indwelling orogastric catheter every 2-3 h. Some of them had a complementary i.v. glucose infusion. The infants were fed before the measurement periods in the incubator and under the radiant heater.

The study was approved by the Ethics Committee of the Medical Faculty of Uppsala University and informed parental consent was obtained for all infants studied.

\section{Measurement Methods}

ER was measured by a method based on determination of the $\mathrm{PH}_{2} \mathrm{O}$ gradient in the air layer close to the skin surface (Evaporimeter EP1, ServoMed AB, Stockholm, Sweden) (19). The method is noninvasive and allows direct, quick, and repeated measurement of ER from the skin without causing discomfort to the infant or interfering with nursing routines $(11,12,19)$. The probe is placed on the skin surface during $1-2$ min for each ER measurement. The method was used earlier in studies of water loss from the skin of newborn infants (15). The equipment for measurement of ER also provides data on $\mathrm{RH}$ (\%) and $\mathrm{PH}_{2} \mathrm{O}(\mathrm{kPa})$. The HR (beats/min) was recorded with an ECG monitor (Hellige, Freiburg, Germany) and the RR (breaths/min) was estimated by 1 -min counting. The ambient air temperature, skin temperatures, and deep rectal temperature were measured with a YSI telethermometer $43 \mathrm{TA}$, using probes 405, 427, and 402 (Yellow Springs Instrument Co., Yellow Springs, OH). The skin thermistors were protected with heat-reflecting patches (Ohio Medical Products, Madison, WI). Air-flow velocity was measured with an air velocity meter (Omnisensor, model 1640, TSI Incorporated, St. Paul, MN). All recordings were made with a Watanabe recording system (Watanabe Instruments Corporation, Tokyo, Japan).

During the measurements the activity state of the infant was observed and graded according to an activity scale with levels of 0 to 5 (19). Measurements were only made when the infant was asleep, or awake and calm with minor motor activity (levels 0 to 2).

\section{Measurement Procedure}

Incubator. The naked infant was nursed in the prone position in a single-walled incubator (AGA MK 241, AGA Medical, Lidingö, Sweden). The incubators were appropriately preheated. At least $30 \mathrm{~min}$ were allowed for the infant to settle down and for the ambient conditions in the incubator to stabilize before the measurements were begun. ER from the skin was measured from an interscapular skin area, the chest, and a buttock. These measurements were repeated two to three times during a period of $30 \mathrm{~min}$. Before each ER measurement, readings of $\mathrm{RH}_{\text {amb }}, \mathrm{PH}_{2} \mathrm{O}_{\text {amb }}, \mathrm{HR}$, and $\mathrm{RR}$ were made. $\mathrm{T}_{\text {body }}$ $\left({ }^{\circ} \mathrm{C}\right)$ was measured with a thermistor inserted about $5 \mathrm{~cm}$ beyond the infant's rectal sphincter. Skin temperatures were measured from the interscapular area $\left(\mathrm{T}_{\text {isc }},{ }^{\circ} \mathrm{C}\right)$ and just below and medial to the knee $\left(\mathrm{T}_{\text {leg }},{ }^{\circ} \mathrm{C}\right) . \mathrm{T}_{\mathrm{amb}}\left({ }^{\circ} \mathrm{C}\right), \mathrm{RH}_{\mathrm{amb}}$, and $\mathrm{PH}_{2} \mathrm{O}_{\text {amb }}$ were measured in the center of the incubator, about $10 \mathrm{~cm}$ above the infant. The system for servo control of skin temperature supplied with the incubator was used to regulate $\mathrm{T}_{\mathrm{amb}}$ by suspending the controlling thermistor in the middle of the incubator above the infant. To keep $\mathrm{T}_{\text {body }}$ as constant as possible within the range $36.5-37.0^{\circ} \mathrm{C}$, the set $\mathrm{T}_{\mathrm{amb}}$ was manually adjusted. The air supply to the incubator was $8-10 \mathrm{~L} / \mathrm{min}$ and the air velocity $5 \mathrm{~cm}$ above the infant was less than $0.1 \mathrm{~m} / \mathrm{s}$. $\mathrm{RH}_{\mathrm{amb}}$ was continuously monitored and maintained at $50 \%$ for all infants during the first 30-min measurement period (period A). For the preterm infants, $\mathrm{RH}_{\mathrm{amb}}$ in the incubator was then lowered to $30-40 \%$ by turning off the humidifier. The aim was to reach a humidity level close to that of the room air. Measurements of ER and environmental variables were then made two to three times during another 30-min period (period B).

Radiant heater. When the measurements in the incubator had been completed, the infant was placed in the prone position on an open bed under an overhead radiant heater (Ohio Medical Products) that had been preheated for at least $15 \mathrm{~min}$. Thirty min or more were allowed for the infant to settle down and to become thermally stable in the environment. Three to five sets of measurements of ER and recordings of ambient conditions were made during a 60 -min period (period C), using 
the methods described above. The $\mathrm{PH}_{2} \mathrm{O}(\mathrm{kPa})$ and air temperature $\left({ }^{\circ} \mathrm{C}\right)$ were measured $15 \mathrm{~cm}$ behind the heater at the level of the infant but shaded from radiation. These environmental conditions could not be adjusted. The air flow velocity $5 \mathrm{~cm}$ above the infant was less than $0.1 \mathrm{~m} / \mathrm{s}$ during the measurements.

According to the manufacturer, the radiant heater has a peak wavelength of 3.8-8 $\mu \mathrm{m}$ and a maximum output of approximately $850 \mathrm{~W}$. To keep $\mathrm{T}_{\text {body }}$ as constant as possible within the range $36.5-37.0^{\circ} \mathrm{C}$, the heater was adjusted manually. Only minor adjustments were needed during the measurement period. The power requirements of the heater were determined by inserting a watt meter between the radiant heater and the electric mains outlet, and the power consumption was between 330 and $660 \mathrm{~W}$. At this level of power consumption, the method for measurement of the ER is not adversely affected (15). Our finding indicate that no influence on the ER measurement occur at $627 \mathrm{~W}$.

\section{Treatment of Data}

The mean ER in an infant was determined as the arithmetical mean of measurements made from the interscapular region, the chest, and a buttock. Transepidermal water loss was determined according to the equation presented earlier (11). Data were also obtained for $\mathrm{T}_{\text {body }}, \mathrm{T}_{\text {isc }}, \mathrm{T}_{\text {leg }}, \mathrm{T}_{\mathrm{amb}}$, air temperature, $\mathrm{RH}_{\mathrm{amb}}, \mathrm{PH}_{2} \mathrm{O}_{\mathrm{amb}}, \mathrm{HR}$, and RR. Statistical testing was done with two-tailed $t$ test on paired observations and, when applicable, anaylsis of variance. The relationship between ER and $\mathrm{PH}_{2} \mathrm{O}_{\text {amb }}$ was determined with the two-point formula, using the ER value and $\mathrm{PH}_{2} \mathrm{O}_{\text {amb }}$ recorded in the incubator at $50 \% \mathrm{RH}$, and the zero $\mathrm{ER}$ value at the saturated $\mathrm{PH}_{2} \mathrm{O}$ at the temperature in the incubator. Accordingly saturated $\mathrm{PH}_{2} \mathrm{O}$ in the air under the radiant heater at the temperature of room air were used for calculation of ER under the radiant heater when ER from the infants' skin in the incubator and under the radiant heater were compared at equal $\mathrm{PH}_{2} \mathrm{O}_{\text {amb }}$.

\section{RESULTS}

Term infants (group I, $n=12$, Table 1). When the infants were nursed in an incubator at $\mathrm{RH}_{\mathrm{amb}}$ of $50 \%($ period $\mathrm{A})$, the mean ER from the skin was $3.2 \pm 0.7$ (SD) $\mathrm{g} / \mathrm{m}^{2} / \mathrm{h}$. When they were nursed under a radiant heater (period C), ER was $4.3 \pm$

Table 1. Term infants (group I, $n=12$ )

\begin{tabular}{|c|c|c|c|c|c|}
\hline & \multicolumn{2}{|c|}{ Period A } & \multicolumn{2}{|c|}{ Period C } & \multirow[b]{2}{*}{$\mathrm{A}-\mathrm{C}, \mathrm{t}$ test } \\
\hline & Mean & SD & Mean & SD & \\
\hline ER & 3.2 & 0.7 & 4.3 & 0.6 & $p<0.001$ \\
\hline $\mathrm{PH}_{2} \mathrm{O}$ & 2.3 & 0.1 & 0.7 & 0.2 & $p<0.001$ \\
\hline $\mathrm{T}_{\text {amb/air }}$ & 33.4 & 1.3 & 28.5 & 1.4 & $p<0.001$ \\
\hline $\mathrm{T}_{\text {body }}$ & 36.8 & 0.2 & 36.8 & 0.2 & NS \\
\hline $\mathrm{T}_{\text {isc }}$ & 35.9 & 0.3 & 35.9 & 0.4 & NS \\
\hline $\mathrm{T}_{\text {leg }}$ & 34.9 & 0.6 & 33.5 & 0.8 & $p<0.001$ \\
\hline $\mathrm{HR}$ & 117.7 & 10.3 & 121.8 & 13.0 & NS \\
\hline $\mathrm{RR}$ & 45.5 & 7.1 & 43.0 & 6.9 & NS \\
\hline
\end{tabular}

Mean values and SD for ER $\left(\mathrm{g} / \mathrm{m}^{2} / \mathrm{h}\right)$, ambient $\mathrm{PH}_{2} \mathrm{O}(\mathrm{kPa})$, air temperatures $\left(\mathrm{T}_{\text {amb/air }} ;{ }^{\circ} \mathrm{C}\right)$, rectal temperature $\left(\mathrm{T}_{\text {body }} ;{ }^{\circ} \mathrm{C}\right)$, skin temperatures $\left(\mathrm{T}_{\text {isc }}, \mathrm{T}_{\text {leg }} ;{ }^{\circ} \mathrm{C}\right)$, HR (beats/min), and RR (breaths/min).
$0.6(\mathrm{SD})$. The difference is statistically significant $(p<0.001)$. The mean $\mathrm{PH}_{2} \mathrm{O}$ in the incubator air was $2.3 \pm 0.1$ (SD) $\mathrm{kPa}$ and in room air $0.7 \pm 0.2(\mathrm{SD})$.

Moderately preterm infants (group II, $n=8$, Table 2). When the moderately preterm infants were nursed in an incubator at $\mathrm{RH}_{\mathrm{amb}}$ of $50 \%$ (period A), mean ER was $7.8 \pm 2.7$ (SD) $\mathrm{g} / \mathrm{m}^{2} / \mathrm{h}$, and at the lower $\mathrm{RH}_{\text {amb }}$ (period B) it was $9.0 \pm$ 3.1 (SD) $\mathrm{g} / \mathrm{m}^{2} / \mathrm{h}(p<0.001)$. Under the radiant heater (period C), mean ER was $8.8 \pm 3.6(\mathrm{SD}) \mathrm{g} / \mathrm{m}^{2} / \mathrm{h}$. The difference between the ER value obtained during care in the incubator at a low humidity level and that obtained during care under the radiant heater is not statistically significant. $\mathrm{Mean} \mathrm{PH}_{2} \mathrm{O}$ in the incubator air was $2.7 \pm 0.2(\mathrm{SD})$ during period $\mathrm{A}$ and $1.5 \pm 0.1$ (SD) during period $\mathrm{B}$. In the room air surrounding the infant during care under the radiant heater (period $\mathrm{C}$ ), mean $\mathrm{PH}_{2} \mathrm{O}$ was $1.2 \pm 0.3(\mathrm{SD})$.

Very preterm infants (group III, $n=8$, Table 3). When very preterm infants were nursed in an incubator at $\mathrm{RH}_{\text {amb }}$ of $50 \%\left(\right.$ period A), mean ER was $23.1 \pm 8.1(\mathrm{SD}) \mathrm{g} / \mathrm{m}^{2} / \mathrm{h}$, and during period $\mathrm{B}$ it was $24.5 \pm 8.4(\mathrm{SD}) \mathrm{g} / \mathrm{m}^{2} / \mathrm{h}$. When they were nursed under the radiant heater (period C), mean ER was $26.8 \pm 7.6(\mathrm{SD}) \mathrm{g} / \mathrm{m}^{2} / \mathrm{h}$. ER was significantly higher during period $\mathrm{C}$ than during period A $(p<0.05)$. There was no significant difference in ER between periods $\mathrm{B}$ and $\mathrm{C}$. The mean $\mathrm{PH}_{2} \mathrm{O}$ of the incubator air was $2.8 \pm 0.3$ (SD) $\mathrm{kPa}$ during period $\mathrm{A}$ and $1.9 \pm 0.3(\mathrm{SD})$ during period $\mathrm{B}$. Mean $\mathrm{PH}_{2} \mathrm{O}$ was $1.3 \pm 0.3(\mathrm{SD})$ in the room air in which the infants were nursed during measurements under the radiant heater (period C).

When the infants were nursed in an incubator at RH $50 \%$, the transepidermal water loss $\left(\mathrm{g} / \mathrm{m}^{2} / \mathrm{h}\right)$, calculated from an equation described previously (11), was $4.3 \pm 0.6(\mathrm{SD})$ in group I, $8.5 \pm 2.5(\mathrm{SD})$ in group II, and $22.6 \pm 7.4$ in group III.

Because the ambient air temperature and humidity could not be kept at the same level under the radiant heater as in the incubator, some calculations had to be made to permit a comparison between the ER values obtained under the two conditions. An example of one such calculation is given in Figure 1. Using the measured values of $\mathrm{ER}$ and $\mathrm{PH}_{2} \mathrm{O}$ in the incubator $\left(E_{\text {inc }}\right.$ in Fig. 1) and the theoretical values of $E R=$ 0 and the $\mathrm{PH}_{2} \mathrm{O}$ in the incubator at an $\mathrm{RH}_{\text {amb }}$ of $100 \%$ at incubator temperature (d in Fig. 1), the highest possible ER is calculated $\left(\mathrm{PH}_{2} \mathrm{O}=0\right)(\mathrm{e})$ from the linear regression line. If the factors influencing the rate of water transport across the skin are unaffected by the environmental conditions, this value will also be the highest possible ER value (f) for the infant under the radiant heater. The regression line for $\mathrm{ER}$ on $\mathrm{PH}_{2} \mathrm{O}$ at the air temperature measured under the radiant heater can then be obtained from this point (f) and the $\mathrm{PH}_{2} \mathrm{O}$ for $\mathrm{RH}=100 \%$ (g). The expected ER for the $\mathrm{PH}_{2} \mathrm{O}_{\text {amb }}$ recorded under the radiant heater is then obtained from this regression line, and can be compared with the actual, measured ER.

In Figure 2, the corresponding measured and calculated values for ER during care under the radiant heater are shown for three representative infants, one from each study group, together with the regression lines for $\mathrm{ER}$ on $\mathrm{PH}_{2} \mathrm{O}$ at the respective air temperatures of the incubator and the radiant heater. In Figure 3, the actual, measured values for ER during 
Table 2. Moderately preterm infants (group II, $n=8$ )

\begin{tabular}{|c|c|c|c|c|c|c|c|c|c|c|}
\hline & \multicolumn{2}{|c|}{ Period A } & \multicolumn{2}{|c|}{ Period B } & \multicolumn{2}{|c|}{ Period C } & \multirow{2}{*}{$\begin{array}{l}t \text { test } \\
\text { A-B }\end{array}$} & \multirow{2}{*}{$\begin{array}{l}t \text { test } \\
\mathrm{A}-\mathrm{C}\end{array}$} & \multirow{2}{*}{$\begin{array}{l}t \text { test } \\
\text { B-C }\end{array}$} & \multirow{2}{*}{$\begin{array}{c}\text { ANOVA } \\
\text { A-B-C }\end{array}$} \\
\hline & Mean & $\mathrm{SD}$ & Mean & $\mathrm{SD}$ & Mean & $\mathrm{SD}$ & & & & \\
\hline ER & 7.8 & 2.7 & 9.0 & 3.1 & 8.8 & 3.6 & $p<0.001$ & NS & NS & NS \\
\hline $\mathrm{PH}_{2} \mathrm{O}$ & 2.7 & 0.2 & 1.5 & 0.1 & 1.2 & 0.3 & $p<0.001$ & $p<0.001$ & $p<0.05$ & $p<0.001$ \\
\hline $\mathrm{T}_{\mathrm{amb} / \mathrm{air}}$ & 35.1 & 1.7 & 35.1 & 2.2 & 24.0 & 1.2 & NS & $p<0.001$ & $p<0.001$ & $p<0.001$ \\
\hline $\mathrm{T}_{\text {body }}$ & 36.7 & 0.2 & 36.8 & 0.2 & 36.7 & 0.1 & NS & NS & NS & NS \\
\hline $\mathrm{T}_{\text {isc }}$ & 36.3 & 0.3 & 36.3 & 0.4 & 36.4 & 0.4 & NS & NS & NS & NS \\
\hline $\mathrm{T}_{\mathrm{leg}}$ & 35.8 & 0.7 & 35.5 & 0.8 & 35.2 & 0.9 & NS & $p<0.01$ & $p<0.01$ & NS \\
\hline $\mathrm{HR}$ & 136.4 & 14.3 & 141.5 & 15.1 & 140.7 & 9.3 & NS & NS & NS & NS \\
\hline $\mathrm{RR}$ & 54.4 & 10.3 & 56.8 & 11.1 & 50.2 & 10.1 & NS & NS & $p<0.01$ & NS \\
\hline
\end{tabular}

Mean values and SD for ER $\left(\mathrm{g} / \mathrm{m}^{2} / \mathrm{h}\right)$, ambient $\mathrm{PH}_{2} \mathrm{O}(\mathrm{kPa})$, air temperature $\left(\mathrm{T}_{\text {amb/air }} ;{ }^{\circ} \mathrm{C}\right)$, rectal temperature $\left(\mathrm{T}_{\text {body }} ;{ }^{\circ} \mathrm{C}\right)$, skin temperatures $\left(\mathrm{T}_{\mathrm{isc}}, \mathrm{T}_{\text {leg; }} ;{ }^{\circ} \mathrm{C}\right)$, $\mathrm{HR}$ (beats/min), and RR (breaths/min). ANOVA, analysis of variance.

Table 3. Very preterm infants (group III, $n=8$ )

\begin{tabular}{|c|c|c|c|c|c|c|c|c|c|c|}
\hline & \multicolumn{2}{|c|}{ Period A } & \multicolumn{2}{|c|}{ Period B } & \multicolumn{2}{|c|}{ Period C } & \multirow{2}{*}{$\begin{array}{c}t \text { test } \\
\text { A-B }\end{array}$} & \multirow{2}{*}{$\begin{array}{l}t \text { test } \\
\text { A-C }\end{array}$} & \multirow{2}{*}{$\begin{array}{c}t \text { test } \\
\text { B-C }\end{array}$} & \multirow{2}{*}{$\begin{array}{c}\text { ANOVA } \\
\text { A-B-C }\end{array}$} \\
\hline & Mean & SD & Mean & $\mathrm{SD}$ & Mean & SD & & & & \\
\hline ER & 23.1 & 8.1 & 24.5 & 8.4 & 26.8 & 7.6 & $p<0.05$ & $p<0.05$ & NS & NS \\
\hline $\mathrm{PH}_{2} \mathrm{O}$ & 2.8 & 0.3 & 1.9 & 0.3 & 1.3 & 0.3 & $p<0.001$ & $p<0.001$ & $p<0.01$ & $p<0.001$ \\
\hline $\mathrm{T}_{\mathrm{amb} / \mathrm{air}}$ & 36.6 & 2.6 & 37.2 & 2.7 & 25.2 & 0.9 & $p<0.05$ & $p<0.001$ & $p<0.001$ & $p<0.001$ \\
\hline $\mathrm{T}_{\text {body }}$ & 36.8 & 0.2 & 36.8 & 0.1 & 36.8 & 0.1 & NS & NS & NS & NS \\
\hline $\mathrm{T}_{\mathrm{isc}}$ & 36.5 & 0.2 & 36.5 & 0.2 & 36.5 & 0.3 & NS & NS & NS & NS \\
\hline $\mathrm{T}_{\text {leg }}$ & 35.9 & 0.6 & 35.7 & 0.5 & 35.5 & 0.5 & $p<0.05$ & NS & NS & NS \\
\hline $\mathrm{HR}$ & 147.1 & 20.2 & 147.5 & 17.7 & 146.8 & 13.2 & NS & NS & NS & NS \\
\hline RR & 55.4 & 7.3 & 52.6 & 11.3 & 54.2 & 8.0 & NS & NS & NS & NS \\
\hline
\end{tabular}

Mean values and SD for ER $\left(\mathrm{g} / \mathrm{m}^{2} / \mathrm{h}\right)$, ambient $\mathrm{PH}_{2} \mathrm{O}(\mathrm{kPa})$, air temperatures $\left(\mathrm{T}_{\text {amb/air }} ;{ }^{\circ} \mathrm{C}\right)$, rectal temperature $\left(\mathrm{T}_{\text {body }} ;{ }^{\circ} \mathrm{C}\right)$, skin temperatures $\left(\mathrm{T}_{\text {isc }}, \mathrm{T}_{\mathrm{leg}} ;{ }^{\circ} \mathrm{C}\right)$, HR (beats/min), and RR (breaths/min). ANOVA, analysis of variance.

care under the radiant heater are compared with the expected ER derived from these calculations for each of the 28 infants. In all but three infants, the measured ER values were lower than the expected, calculated ER.

In all three groups, the average measured ER under the radiant heater was significantly lower than the expected ER. The difference was $0.86 \pm 0.82$ (mean $\pm \mathrm{SD} ; p<0.01$ ) in group I, $2.25 \pm 1.66(p<0.01)$ in group II, and $2.91 \pm 2.39$ $(p<0.01)$ in group III.

\section{DISCUSSION}

Our main finding was that the water loss from the skin depends on the ambient vapor pressure when an infant is nursed in an incubator and when he or she is nursed under a radiant heater. This observation was made for term and preterm infants, and the lower ER from the skin of infants born at term compared with that from preterm infants is in accordance with earlier reports (13). To exclude the possibility that convective air currents may have influenced the water loss from the skin as described by Baumgart et al. (10), Okken et al. (21), and Thompson et al. (22), we tried to avoid drafts in the room where the measurements were made. In our study, the air velocity above the infant was less than $0.1 \mathrm{~m} / \mathrm{s}$ at the time of the ER measurements both in the incubator and under the radiant heater, which makes comparisons of ER values obtained in these two environments appropriate. The air velocity close to the skin of the infant nursed under a radiant heater in an intensive care unit may be higher and might disturb the rate of diffusion and increase ER. In addition, the amount of heat supplied (convective/radiative) was carefully controlled to avoid subjecting the infant to thermal stress and to minimize the risk of "nonvisible" sweating. $\mathrm{T}_{\text {body }}$ and $\mathrm{T}_{\text {isc }}$ were at the same level in all measurement periods in each of the three groups of infants studied, but $\mathrm{T}_{\text {leg }}$ was lower in groups I and II during care under the radiant heater than in the incubator at $\mathrm{RH}$ of $50 \%$.

Wheldon and Rutter (17) considered that the higher ER from the skin of moderately preterm infants during care under a radiant heater compared with nursing in an incubator was not due to a difference in ambient humidity but to a change in the resistance of the skin itself to water vapor diffusion. However, in their study the water vapor concentration under the radiant heater was only $83.6 \%$ of that in the incubator. Thus, in the study by Wheldon and Rutter (17), the higher water loss from the skin of preterm infants nursed under a radiant heater compared with that during nursing in an incubator could have been due to differences in vapor pressure.

Wheldon and Rutter (17) also found that infants had a significantly higher oxygen consumption (21\%) when nursed under a radiant heater than when nursed in an incubator, but the respiratory water loss was the same in these two environments. The authors considered the higher oxygen consumption to be due to a higher level of activity of the infants under the radiant heater or to a more uneven distribution of skin temperature. These infants were thus not in a very stable condition regarding activity, but it is impossible to determine whether the described small change in activity could have influenced the water loss from the skin. In term infants, increased activity causes an 


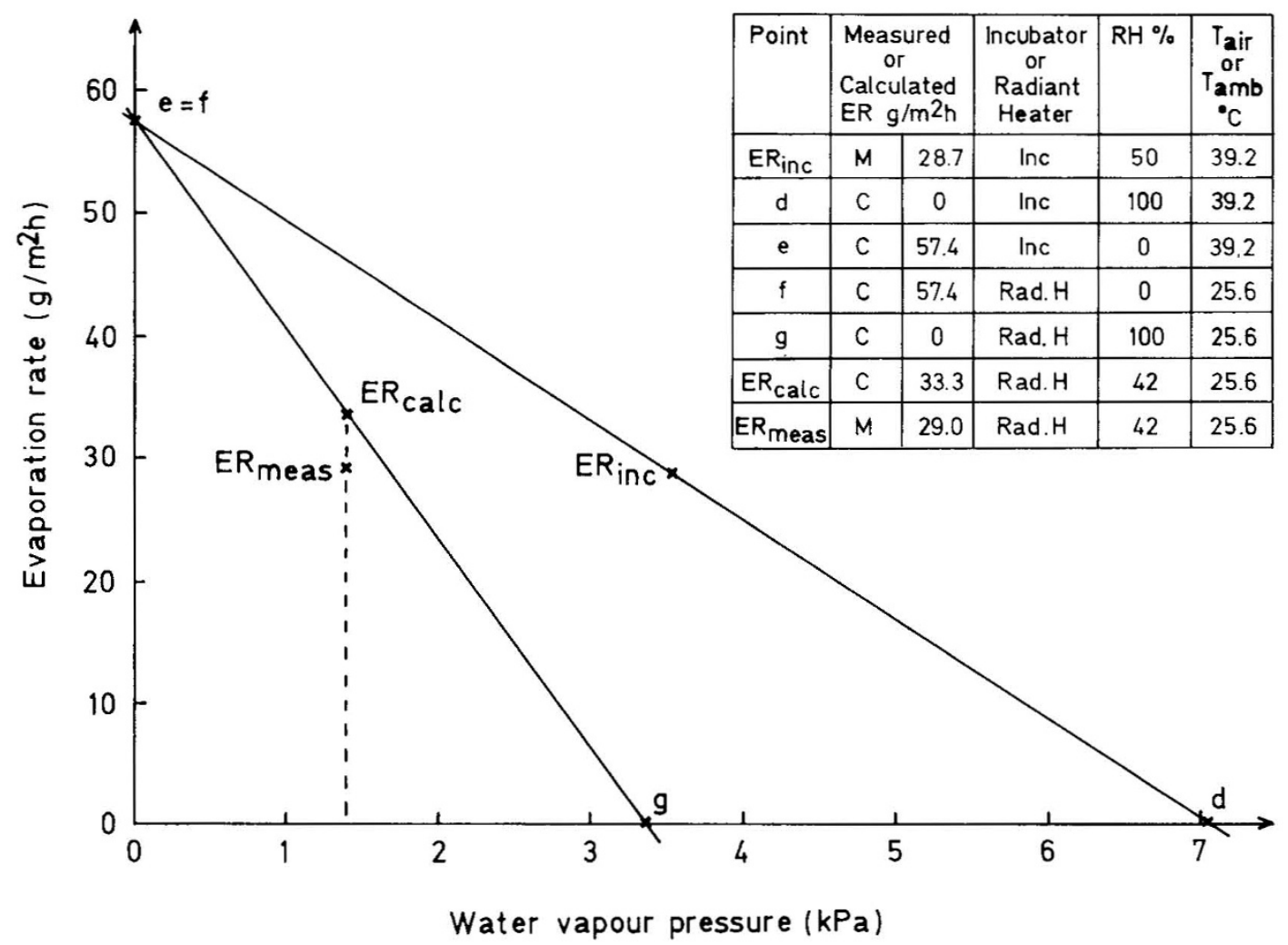

Figure 1. Theoretical regression lines for $\mathrm{ER}$ on $\mathrm{PH}_{2} \mathrm{O}$ during care in an incubator (lines $d$ and $e$ ) and under a radiant heater (lines $f$ and $g$ ) for an infant in group III. The calculated ER $\left(\mathrm{ER}_{\text {calc }}\right)$ under the radiant heater is higher than the measured $\mathrm{ER}\left(\mathrm{ER}_{\text {meas }}\right)$. For an explanation of the calculations, see text.

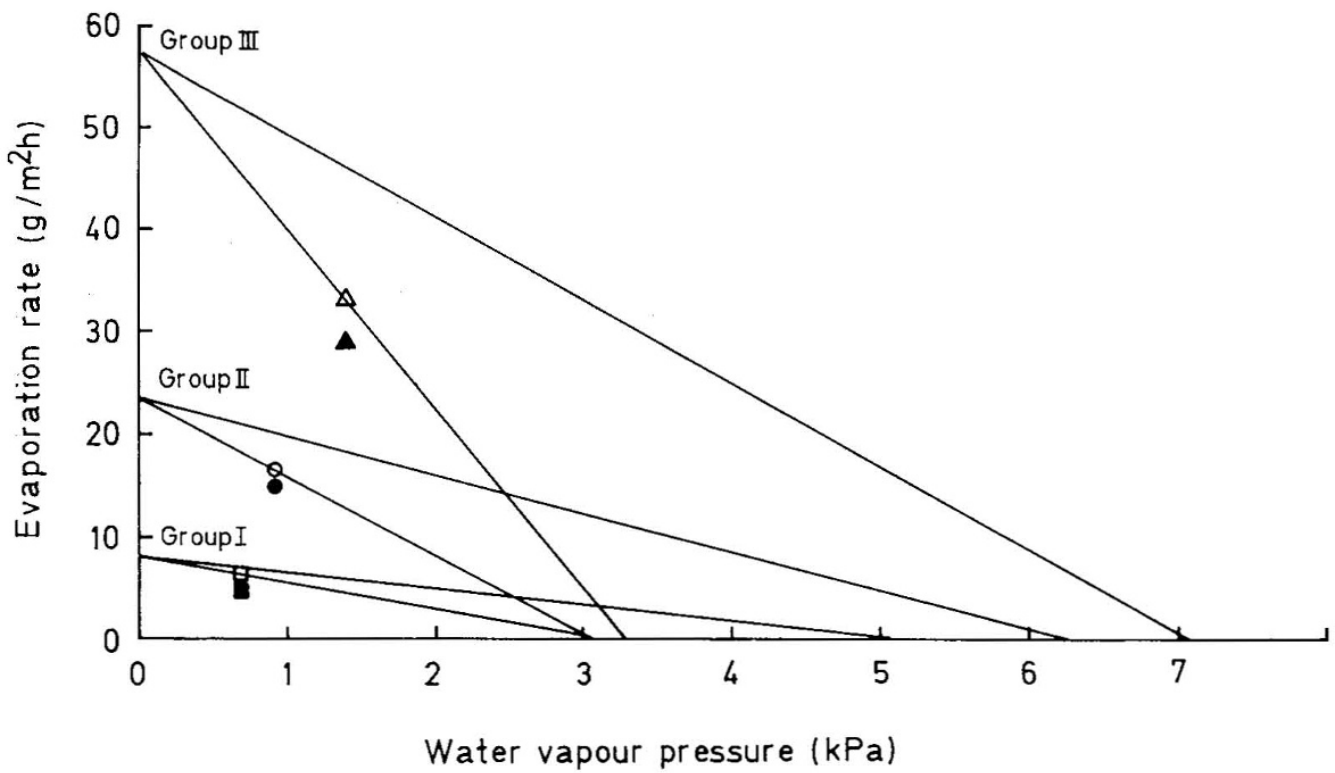

Figure 2. The calculated (open symbols) and measured (filled symbols) values for $\mathrm{ER}\left(\mathrm{g} / \mathrm{m}^{2} / \mathrm{h}\right)$ during care under a radiant heater, together with the corresponding regression lines for ER on $\mathrm{PH}_{2} \mathrm{O}$ at the air temperatures of the incubator and the radiant heater, in three infants, one from each of the study groups I-III. For an explanation of the calculations, see text and Figure 1.

increase in the ER from the skin (23) and leads to an increase in respiratory water loss and in oxygen consumption (20). This is the reason why, in our study, only measurements made when the infant was asleep or awake with minor motor activity were accepted.

Because it is well documented from our previous studies that the evaporation of water from the skin depends on the envi- ronmental humidity $(12,13)$, all comparisons should be made under equivalent conditions regarding the $\mathrm{PH}_{2} \mathrm{O}$ of the ambient air. When preterm infants were studied, the ambient humidity in the incubator was lowered in an attempt to reach the $\mathrm{PH}_{2} \mathrm{O}$ level that was found in the air under the radiant heater. The infants had a water loss from the skin of the same magnitude when nursed at a low ambient humidity in an incubator as 


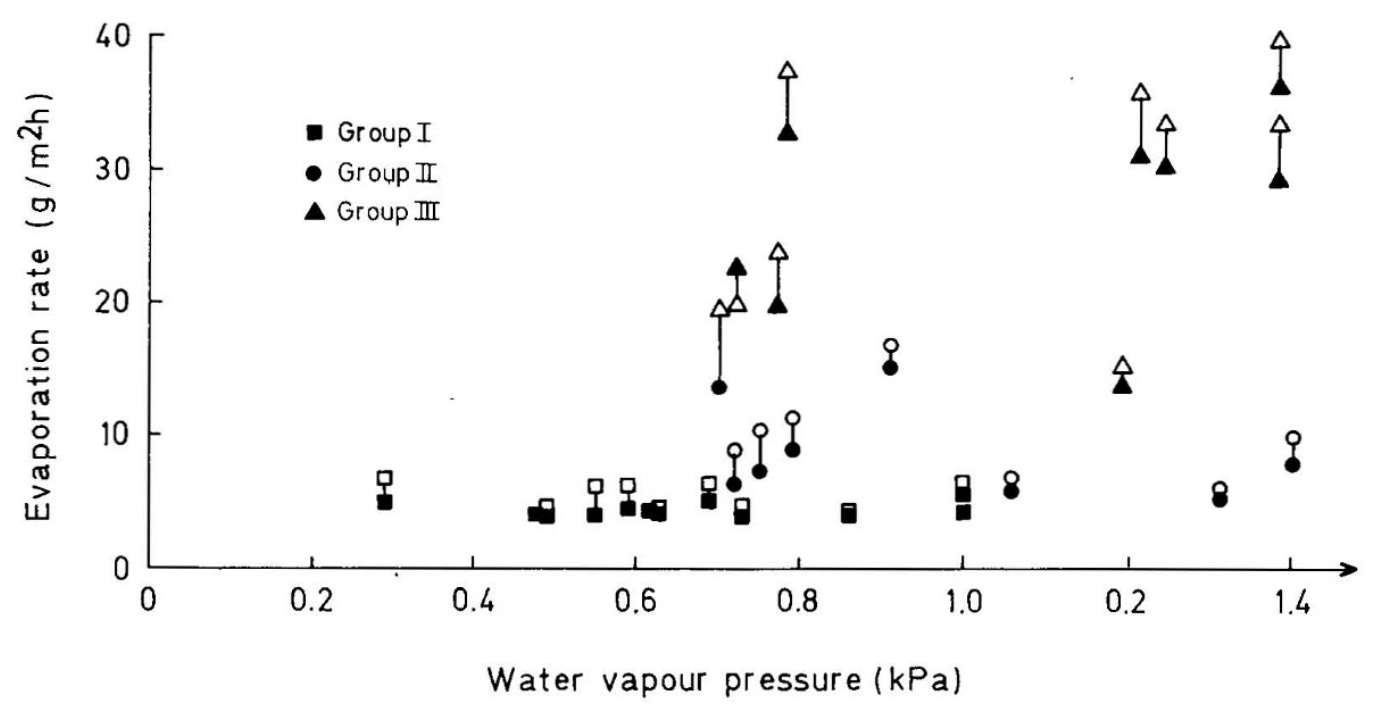

Figure 3. The calculated (open symbols) and measured (filled symbols) values for ER $\left(\mathrm{g} / \mathrm{m}^{2} / \mathrm{h}\right)$ during care under the radiant heater for each of the infants in groups I $(n=12)$, II $(n=8)$, and III $(n=8)$. For an explanation of the calculations, see text and Figure 1 .

when nursed under a radiant heater. As shown above, the ER measured from the skin of infants when nursed under the radiant heater was lower than that expected from the $\mathrm{PH}_{2} \mathrm{O}$ and the temperature of the air surrounding the radiant heater (Figs. 1-3). This implies that the higher ER found under the radiant heater is caused by the lower $\mathrm{PH}_{2} \mathrm{O}_{\text {amb }}$ and not by any increase in the permeability or transporting capacity of the skin caused by the nonionizing radiation emitted by the radiant heater.

Our results support the view that the increase in insensible water loss found in earlier studies (2-7) during nursing under a radiant heater may have been due to a lower ambient humidity, as suggested by Williams and Oh (2) and Bell and $\mathrm{Oh}$ (9). It cannot be excluded that factors such as convective air currents or increased motor activity, which were kept well under control in our study, could have contributed to the higher water losses found in some studies (2-6) during care under a radiant heater compared with those during care in an incubator.

The conclusions drawn from our findings have to be restricted to water loss from the skin. Additional studies are required to ascertain that the respiratory water loss in thermally stable infants is not higher during care under a radiant heater than during care in an incubator.

The ER from the skin of newborn infants in thermal balance depends on the $\mathrm{PH}_{2} \mathrm{O}_{\text {amb}}$, irrespective of whether the infant is nursed in an incubator or under a radiant heater. Higher ER under radiant heaters are due to lower ambient humidities and not to any direct effect of nonionizing radiation on the infant's skin.

Acknowledgments. The authors thank Barbro Kjällström for skillful assistance.

\section{REFERENCES}

1. Bell EF 1983 Infant incubators and radiant warmers. Early Hum Dev 8:351-375

2. Williams PR, Oh W 1974 Effects of radiant warmer on insensible water loss in newborn infants. Am J Dis Child 128:511-514

3. Wu PYK, Hodgman JE 1974 Insensible water loss in preterm infants: changes with postnatal development and non-ionizing radiant energy. Pediatrics 54:704-711
4. Bell EF, Neidich GA, Cashore WJ, Oh W 1979 Combined effect of radiant warmer and phototherapy on insensible water loss in low-birth-weight infants. J Pediatr 94:810-813

5. Marks KH, Gunther RC, Rossi A, Maisels MJ 1980 Oxygen consumption and insensible water loss in premature infants under radiant heaters. Pediatrics $66: 228-$ 232

6. Bell EF, Weinstein MR, Oh W 1980 Heat balance in premature infants: comparative effects of convectively heated incubator and radiant warmer, with and without plastic heat shield. J Pediatr 96:460-465

7. Baumgart S, Engle WD, Fox WW, Polin RA 1981 Radiant warmer power and body size as determinants of insensible water loss in the critically ill neonate. Pediatr Res 15:1495-1499

8. Baumgart S 1982 Radiant energy and insensible water loss in the premature newborn infant nursed under a radiant warmer. Clin Perinatol 9:483-503

9. Bell EF, Oh W 1987 Fluid and electrolyte management. In: Avery GB (ed) Neonatology, Pathophysiology and Management of the Newborn, 3rd Ed. JB Lippincott, Philadelphia, pp 778-779

10. Baumgart S, Engle WD, Fox WW, Polin RA 1981 Effect of heat shielding on convective and evaporative heat losses and on radiant heat transfer in the premature infant. J Pediatr 99:948-956

11. Nilsson G, Sedin G, Öberg $\AA 1975$ A transducer for measurement of evaporation from the skin. Proceedings of the International Conference on Biomedical Transducers, Paris, France, 3-7/11 Part II:71-77

12. Hammarlund K, Nilsson G, Öberg PÅ, Sedin G 1977 Transepidermal water loss in newborn infants. I. Relation to ambient humidity and site of measurement, and estimation of total transepidermal water loss. Acta Paediatr Scand 66:553-562

13. Hammarlund K, Sedin G 1979 Transepidermal water loss in newborn infants. III. Relation to gestational age. Acta Paediatr Scand 68:795-801

14. Hammarlund K, Strömberg B, Sedin G 1982 Transepidermal water loss in newborn infants. VII. Relation to post-natal age in very preterm and full-term appropriate for gestational age infants. Acta Paediatr Scand 71:369-374

15. Sedin G, Hammarlund K, Nilsson GE, Strömberg B, Öberg PÅ 1985 Measurements of transepidermal water loss in newborn infants. Clin Perinatol 12:79-99

16. Kjartansson S, Hammarlund K, Öberg PÅ, Sedin G 1991 Does non-ionizing radiant energy affect determination of the evaporation rate by the gradient method? Ups $J$ Med Sci 96:35-46

17. Wheldon AE, Rutter N 1982 The heat balance of small babies nursed in incubators and under radiant warmers. Early Hum Dev 6:131-143

18. Kjartansson S, Hammarlund K, Sedin G 1992 Insensible water loss from the skin during phototherapy in term and preterm infants. Acta Paediatr 81:764-768

19. Nilsson GE 1977 Measurement of water exchange through the skin. Med Biol Eng Comput 15:209-218

20. Riesenfeld T, Hammarlund K, Sedin G 1987 Respiratory water loss in relation to activity in fullterm infants on their first day after birth. Acta Paediatr Scand 76:889893

21. Okken A, Blijham C, Franz W, Bohn E 1982 Effects of forced convection of heated air on insensible water loss and heat loss in preterm infants in incubators. J Pediatr 101:108-112

22. Thompson MH, Stothers JK, McLellan NJ 1984 Weight and water loss in the neonate in natural and forced convection. Arc Dis Child 59:951-956

23. Hammarlund K, Nilsson G, Öberg PÅ, Sedin G 1979 Transepidermal water loss in newborn infants. II. Relation to activity and body temperature. Acta Paediatr Scand 68:371-376 